\title{
Synthesis of Petroleum-Based Fuel from Waste Plastics and Performance Analysis in a CI Engine
}

\author{
Christine Cleetus, ${ }^{1}$ Shijo Thomas, ${ }^{2}$ and Soney Varghese ${ }^{2}$ \\ ${ }^{1}$ Department of Mechanical Engineering, NIT Calicut, Kerala 673601, India \\ ${ }^{2}$ School of Nano Science and Technology, NIT Calicut, Kerala 673601, India \\ Correspondence should be addressed to Shijo Thomas; tshijo2004@gmail.com
}

Received 26 February 2013; Revised 18 June 2013; Accepted 18 July 2013

Academic Editor: Gang Quan

Copyright (c) 2013 Christine Cleetus et al. This is an open access article distributed under the Creative Commons Attribution License, which permits unrestricted use, distribution, and reproduction in any medium, provided the original work is properly cited.

\begin{abstract}
The present work involves the synthesis of a petroleum-based fuel by the catalytic pyrolysis of waste plastics. Catalytic pyrolysis involves the degradation of the polymeric materials by heating them in the absence of oxygen and in the presence of a catalyst. In the present study different oil samples are produced using different catalysts under different reaction conditions from waste plastics. The synthesized oil samples are subjected to a parametric study based on the oil yield, selectivity of the oil, fuel properties, and reaction temperature. Depending on the results from the above study, an optimization of the catalyst and reaction conditions was done. Gas chromatography-mass spectrometry of the selected optimized sample was done to find out its chemical composition. Finally, performance analysis of the selected oil sample was carried out on a compression ignition (CI) engine. Polythene bags are selected as the source of waste plastics. The catalysts used for the study include silica, alumina, Y zeolite, barium carbonate, zeolite, and their combinations. The pyrolysis reaction was carried at polymer to catalyst ratio of $10: 1$. The reaction temperature ranges between $400^{\circ} \mathrm{C}$ and $550^{\circ} \mathrm{C}$. The inert atmosphere for the pyrolysis was provided by using nitrogen as a carrier gas.
\end{abstract}

\section{Introduction}

In the recent years it is quite common to find in newspapers and publications that plastics are turning out to be a menace. Days are not so far when earth will be completely covered with plastics and humans will be living over it. All the reasoning and arguments for and against plastics finally land up on the fact that plastics are nonbiodegradable in nature. The disposal and decomposition of plastics has been an issue which has caused a number of research works to be carried out in this regard. Currently the disposal methods employed are land filling, mechanical recycling, biological recycling, thermal recycling, and chemical recycling. Of these methods, chemical recycling is a research field which is gaining much interest recently, as it turns out to be that the products formed in this method are highly advantageous.

Plastic is one such commodity that has been so extensively used and is sometimes referred to as one of the greatest innovations of the millennium. There are a numerous ways in which plastic is and will continue to be used. The plastic has achieved such an extensive market due to fact that it is lightweight, cheap, flexible, reusable, do not rust or rot, and so forth. Because of this, plastics production has gone up by almost $10 \%$ every year on a global basis since 1950 [1]. Asia accounts for $36.5 \%$ of the global consumption and has been world's largest plastics consumer for several years. The major segment continues to be the packaging, which has accounted for over $35 \%$ of the global demand [2]. The global per capita consumption of plastics is shown in Figure 1.

The global production of plastics has seen an increase from around 1.3 million tonnes in 1950 to $245 \mathrm{MT}$ in 2006 [1]. In recent years, significant growth in the consumption of plastic globally has been due to the introduction of plastics into newer application areas such as in automotive field, rail, transport, aerospace, medical and healthcare, electrical and electronics, telecommunication, building and infrastructure, and furniture. This significant growth in the demand for plastic and its forecast for future have certainly proved that there has been a quiet plastic revolution taking place in every sector. 


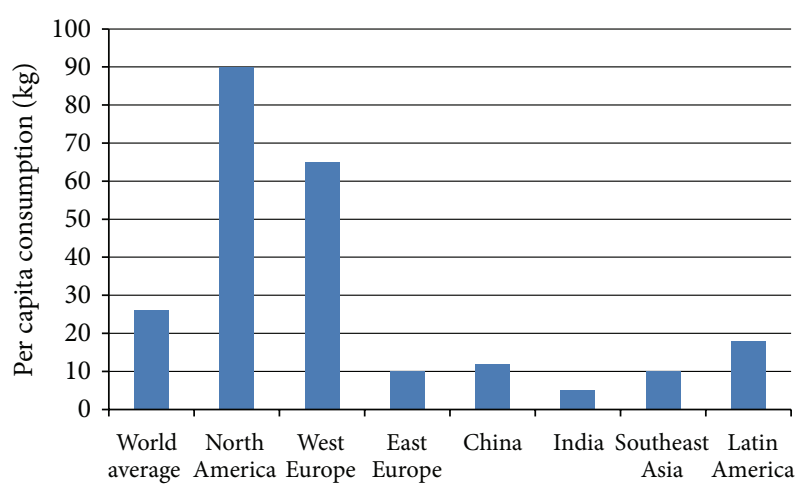

FIGURE 1: Global per capita consumption of plastics [2].

TABLE 1: Global consumption of individual plastics [2].

\begin{tabular}{lc}
\hline Type of plastic & Consumption \% \\
\hline Polythene (PE) & 33.5 \\
Polypropylene (PP) & 19.5 \\
Polyvinylchloride (PVC) & 16.5 \\
Polystyrene (PS) & 8.5 \\
$\begin{array}{l}\text { Polyethylene terephthalate (PET) and } \\
\text { polyurethane (PU) }\end{array}$ & 5.5 \\
$\begin{array}{l}\text { Styrene copolymers (ABS, SAN, etc.) } \\
\text { Blends, alloys, high performance and specialty } \\
\text { plastics, thermosetting plastics, and so forth }\end{array}$ & 3.5 \\
\hline
\end{tabular}

As far as the individual plastics materials are concerned, polyolefins account for $53 \%$ of the total consumption. The consumption of the individual plastic materials is shown in the Table 1. It can be seen that one-third of the global consumption of plastic is polythene. The growth in the global polythene demand is estimated to be around $4.4 \%$ annually up to 2020 [2]. This is the reason behind the selection of polythene as the source of waste plastic in this study.

The increase in the rate of plastic consumption throughout the world has led to the creation of more and more amounts of waste, and this in turn poses greater difficulties for disposal. This is because the life duration of plastic (the time period for which the plastic remains in use) is very small. About $40 \%$ of plastics consumed have duration of life smaller than one month. The service life of plastic products ranges from 1 to 35 years depending on the area of application. In India, the weighted average service life of all plastics products comes to about 8 years. This may vary among countries depending on the type of consumption. This short service life in India reflects that a major share of the plastic consumed here is short-life products. This can be accounted for as the share of plastics used in packaging which is $42 \%$ [1].

\section{Different Methods of Plastic Waste Management}

The suitable treatment of plastic is the most important factor in waste plastic management. This is quite important from the energetic, environmental, and economic point of view. Even though the recycling rate for postconsumer plastics has increased in the recent years, this increase has been only meager coming to only around $1.5 \%$. This increase in the recycling is due to the strict legal regulations and growing awareness. Different techniques for the waste plastic management are being followed today [1].

The major portion of the waste plastics has been subjected to landfill. Such a disposal of the waste to landfill is now strictly regulated legally. The regulations are expected to achieve a reduction of $35 \%$ in land filling over the period from 1995 to 2020 . Also the rising cost and scarcity of land, the generation of explosive greenhouse gases (such as methane), a high volume to weight ratio of plastics, and the poor biodegradability of commonly used packaging polymers also make it an unattractive option.

Reprocessing of the used plastics to form new similar products is termed as mechanical recycling. In this method, the products obtained are with almost same or less performance level than the original product. Even if the technique seems to be "a green operation," it is not cost effective as it requires high energy for cleaning, sorting, transportation, and processing to make a serviceable product. Practically it is seen that reprocessing of mixed contaminated plastics yields mechanically inferior products lacking in durability compared with the original polymers.

Biodegradable polymers are those which can be converted back to the biomass in a realistic time period. However, there are a number of difficulties over the use of degradable plastics. First, appropriate conditions are necessary for the degradation of such plastics, such as presence of light for the photodegradable plastics. Second, greenhouse gases such as methane is released when plastics degrade anaerobically. This is by enabling microorganisms in the environment to metabolize the molecular structure of plastic films to produce an inert humus-like material that is less harmful to the environment.

Incineration of plastics waste is an alternate method in which energy is recovered from waste polymers. These hydrocarbon polymers can replace fossil fuels and thereby reduce the $\mathrm{CO}_{2}$ burden on the environment. Polyethylene is having calorific value similar to that of the fuel oil, and the energy produced by incineration of polyethylene is of the same order as that used in its manufacture making it an attractive option. However, this method produces green house gases and toxic pollutants giving it a big disadvantage.

Cracking process breaks down the long polymeric chains into useful smaller molecular weight compounds. The products of this process are highly useful and can be utilized as fuels or chemicals in various applications. The pyrolysis reaction can be carried out without or in the presence of a catalyst. If without catalyst, it is thermal cracking or thermolysis, and if in the presence of catalyst, it is catalytic pyrolysis.

Thermal cracking or pyrolysis involves the degradation or cracking of the polymeric materials by heating them to a very high temperature. The heating should be carried out in the absence of oxygen to make sure that no oxidation of the polymer takes place. The temperature ranges between 350 and $900^{\circ} \mathrm{C}$. The products formed include a carbonized char 
(solid residues) and a volatile fraction. A portion of the volatile fraction can be condensed to give paraffins, isoparaffins, olefins, naphthenes, and aromatics, while the remaining is a noncondensable high calorific value gas. The products formed and their precise composition depend on the type of the plastic waste and the process conditions. In catalytic cracking, the same process is carried out in the presence of a catalyst. The prominent advantage of this method is that the presence of catalyst lowers the reaction temperature and time. Another added advantage is that in thermal cracking a broad variety of products are formed by the braking of the polymeric chain, while in catalytic degradation the product distribution will be a much narrower, with a peak at lighter hydrocarbons. From the economic point of view also, reducing the cost even further will make this process more attractive. Due to these reasons in the present work, this method is adopted for the synthesis of petroleumbased oil. The importance of this work lies in comparing the performance of different catalysts like barium carbonate, zeolite 1 (pore size $\sim 4 \AA$ ), silica alumina 1 (SA1) (silica ( $30 \mathrm{~nm}) 83.3 \%$, alumina $(\sim 30 \mathrm{~nm}) 16.7 \%)$, silica alumina 2 (SA2) (silica $21.1 \%$, alumina 78.9\%), SA1 + Z1 (70\% SA1, $30 \% \mathrm{Zl}$ ), and zeolite 2 (sodium Y zeolite) for the thermal cracking of waste polythene and selecting the most suitable catalyst based on the yield and thermophysical properties of the hydrocarbon oil obtained.

\section{Literature Review}

A lot of research has been done in noncatalytic and catalytic pyrolyses of plastics which proves that plastics waste can indeed be converted to useful chemical feedstock. The works reveal that the product distribution can be affected by a number of parameters which include the polymer source (plastic type), catalysts used, size of the catalyst, catalyst to polymer ratio, reaction temperature, reaction time, and reactor type. The effect of various process variables is described below.

3.1. Effect of Catalyst. The catalyst used in the pyrolysis of plastics definitely influences the product. The most commonly used catalysts in the literature for plastic waste pyrolysis includes silica alumina, zeolites (beta, USY, ZSM-5, REY, clinoptilolite, etc.), and MCM-41. With increasing number of acid sites, the level of the catalyst activity in polyolefin pyrolysis also increases. Thus, zeolite-based catalysts due to their high acid strength achieve higher conversion than nonzeolitic catalysts. Songip et al. [3] studied the conversion of polyethylene to transportation fuel using HY, rare earth metalexchanged Y-type (REY), and HZSM-5 zeolites and silicaalumina (SA). It was found that REY zeolite was the most suitable catalyst producing plastic oil with the highest octane number and gasoline yield. REY had large pores and had proper acidic strength which made it the most suitable one. Y zeolite and ZSM-5 zeolite produced oils having a high research octane number comparable to that of the oil by REY, but the gasoline yield by the formers was significantly low as compared to REY. The catalytic degradation of polyethylene by ultrastable-Y zeolite was studied by Manos et al. [4]. Low pyrolysis temperature does not cause the polymer to fully degrade, and a solid residue is produced in the reaction bed. It showed that the catalyst has significantly reduced the degradation temperature as compared with pure thermal degradation in the absence of a catalyst. The products of the catalytic degradation were hydrocarbons in the $\mathrm{C}_{3}-\mathrm{C}_{15}$ range. The catalyst was highly acidic, producing oil with high octane number. A number of research works have been done to find out the effect of silica alumina as catalyst for the pyrolysis of plastics. It can be seen that with silica alumina, high liquid yield can be obtained. The effects of silica alumina with two different $\mathrm{SiO}_{2} / \mathrm{Al}_{2} \mathrm{O}_{3}$ proportions; that is, $\mathrm{SA}-1\left(\mathrm{SiO}_{2} / \mathrm{Al}_{2} \mathrm{O}_{3}\right.$ ratio of 83.3/16.7) and silica alumina SA-2 $\left(\mathrm{SiO}_{2} / \mathrm{Al}_{2} \mathrm{O}_{3}=\right.$ 21.1/78.9) were studied by Uddin et al. [5]. The liquid yield was found to be $68 \mathrm{wt} \%$ for SA-1 as compared to $77 \mathrm{wt} \%$ for SA-2. Therefore, the SA-1 catalyst degraded the polyethylene sample into much lighter hydrocarbon fuel oil than the SA-2 catalyst. Thus it can be concluded that the yield and composition of the liquid products can be controlled by altering the $\mathrm{SiO}_{2} / \mathrm{Al}_{2} \mathrm{O}_{3}$ ratio. The liquid products are distributed in $\mathrm{C}_{5}-\mathrm{C}_{20}$ range, that is, basically in the gasoline and diesel ranges. The effect of nonacidic catalysts for the pyrolysis of plastics was studied by Jan et al. [6]. On comparison with $\mathrm{MgCO}_{3}$ when used as a catalyst under $450^{\circ} \mathrm{C}$, it could be observed that the \% oil yield (33.60\%) is higher with $\mathrm{MgCO}_{3}$ as compared to the \% oil yield $(29.60 \%)$ obtained with $\mathrm{BaCO}_{3}$ catalyst. Similarly when $\mathrm{CaCO}_{3}$ was used as a catalyst under the same reaction conditions, the obtained $\%$ oil yield was $32.20 \%$.

3.2. Effect of Catalyst Contact Mode. There exist two methods by which catalyst can be added to the pyrolysis reactor: liquid phase contact and vapor phase contact. In the liquid phase contact, the catalyst and polymer are mixed together, and then they are placed in the reactor and heated to the reaction temperature. However, in the vapor phase contact, the polymer is first subjected to thermolysis to produce the volatile fraction. The catalyst is inserted in the path of the moving vapour, and as the vapour moves through the catalyst, the hydrocarbon vapour is degraded to get the required product distribution. However, the product yield is reported not to differ significantly with the two modes [1].

3.3. Effect of Polymer to Catalyst Ratio. Effect of polymer to catalyst ratio has been studied by Akpanudoh et al. [7]. It has been concluded that with the increase in the amount of catalyst, a direct proportionality in terms of the effectiveness is not obtained. The increase in catalyst amount increases the conversion up to particular limit, but a further increase in the catalyst percentage does not give any appreciable increase in the conversion rate. The optimum polymer to catalyst ratio as obtained from studies is $4: 1$. However, it is also found in the literature that a lesser catalyst ratio will also provide similar degradation, but only at higher reaction temperatures [8]. Some kind of optimisation has to be done with the catalyst ratio and temperature, so that the operation remains economical too.

3.4. Effect of Temperature. If the catalytic pyrolysis is taking place at higher operating temperature or at high heating rates, it causes the enhancement of bond breaking and thereby 


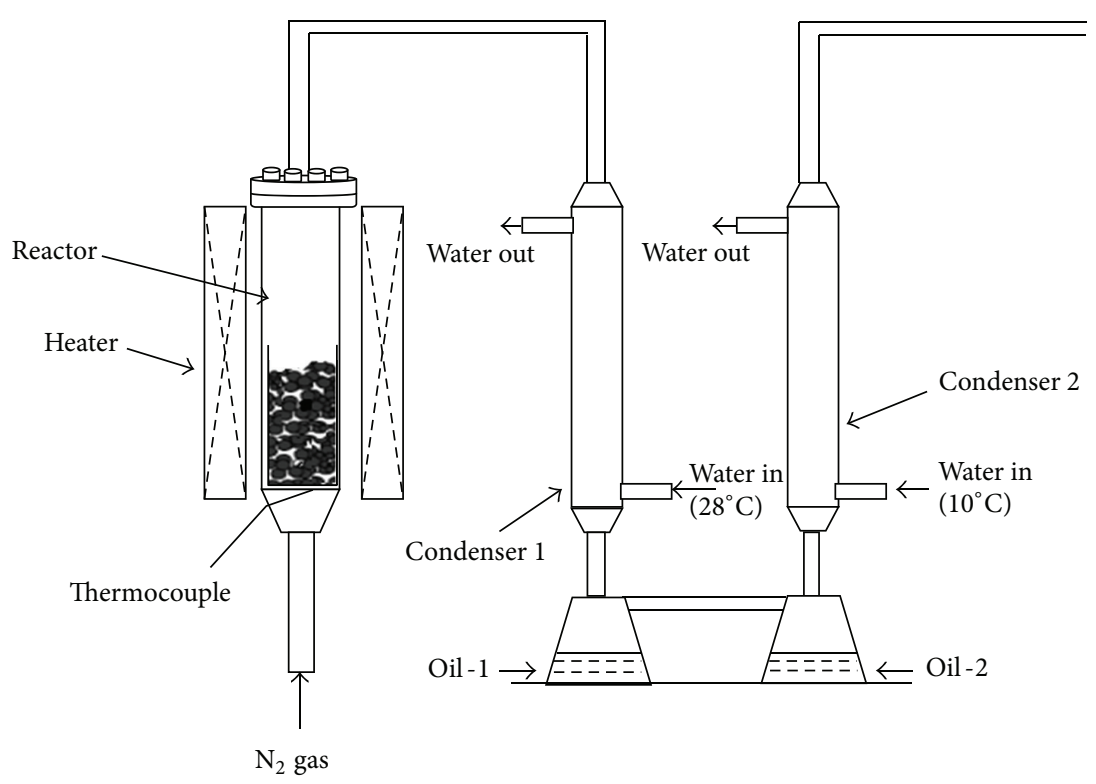

FIGURE 2: Schematic model of the experimental setup.

favouring the production of smaller molecules. The extend of conversion increases with increase of temperature, and it can be seen that with higher conversion the major products formed will be the gaseous products and the liquid yield being minimum or nil. The effect of different catalysts on the liquid yield and the product distribution becomes less significant with increasing temperature. The reaction taking place will be similar to thermal degradation [8].

3.5. Effect of Flow Rate of Nitrogen Gas. The inert gas flowing through the reaction does not affect the reaction directly, but it can produce a slight change in the liquid yield. Usually the nitrogen flow rate was chosen to be relatively high, in order to move the volatile primary products from the reactor and keep secondary reactions at a minimum. This actually favours the liquid yield. But studies of Gulab et al. [8] indicate that high carrier gas flow rate can enhance the evaporation of liquid products which are collected in the condenser. This falsifies the results of liquid yield. By course of experiments, it has been found that the optimum flow rate is $10 \mathrm{~mL} / \mathrm{min}$.

The objective of the present work is to synthesize petroleum based fuel by the catalytic pyrolysis of waste plastics using different catalysts, optimization of the yield based on catalyst and reaction conditions, and its performance analysis in an IC engine.

\section{Waste Plastic Oil Production}

Polythene is selected as the source of waste plastics since it comprises a prominent percentage of the waste plastic produced. The catalysts identified for the study include silica alumina, zeolites, barium carbonate, titanium chloride, and their combinations. The pyrolysis reaction is carried out in the polymer to catalyst ratio of $4: 1$. The reaction temperature ranges between 350 and $450^{\circ} \mathrm{C}$. The inert atmosphere for the pyrolysis is provided by using nitrogen as a carrier gas, and the flow rate is fixed to be $10 \mathrm{~mL} / \mathrm{min}$. These selections have been made on the basis of the literature survey that has been carried out. A schematic sketch of the experimental setup is as shown in Figure 2. The setup consists of a ceramic electric heater (reactor), a steel container, two condensers, two oil collectors, and a nitrogen source (inert gas). The maximum loading capacity of the reactor was $1.5 \mathrm{~kg}$ of waste plastics. The reactor consists of three ceramic heaters, each having power of $2000 \mathrm{~W}$, arranged in series over a cast iron pipe of $17 \mathrm{~cm}$ diameter and $60 \mathrm{~cm}$ length. The double pipe counter flow heat exchanger of length $90 \mathrm{~cm}$ functions as the condenser. Water at around $28^{\circ} \mathrm{C}$ (room temperature) is used as the coolant in the first condenser, and the temperature of water being supplied to the second heat exchanger is $10^{\circ} \mathrm{C}$. The waste plastic is placed inside a steel container of $15 \mathrm{~cm}$ diameter and $20 \mathrm{~cm}$ height at a packing density of $424 \mathrm{~kg} / \mathrm{m}^{3}$. This container is finally placed inside the heater. The purpose of this container is to avoid the flow of melted waste plastic downwards under gravity as such a flow can block the passage of the nitrogen gas.

The waste plastic was mixed with the catalyst in a twin roll mill, before it is being supplied to the heater. During the mixing process the plastic gets heated enough to get devoid of any moisture content. The reactor was fixed vertically, and nitrogen gas was introduced into the reactor from the bottom. The flow of nitrogen replaces the air from the reactor and permits the pyrolysis reaction under anaerobic condition. Before starting the heating, nitrogen gas is allowed to flow through the heater unit to remove the oxygen that is present initially. Then heater is switched on, and the temperature controller is set to the required operational temperature. The vapor fraction formed during the pyrolysis of the plastic inside the reactor flows out along with $\mathrm{N}_{2}$ out of the reactor. The gas mixture is first cooled in the condenser 1. Ordinary room 
TABLE 2: Optimum properties of plastic oil with different catalysts.

\begin{tabular}{|c|c|c|c|c|c|c|c|}
\hline Catalyst & None & $\mathrm{BaCO}_{3}$ & $\mathrm{Z1}$ & SA1 & SA2 & $\mathrm{SA} 1+\mathrm{Z} 1$ & $\mathrm{Z} 2$ \\
\hline Temp. $\left({ }^{\circ} \mathrm{C}\right)$ & 450 & 450 & 450 & 425 & 450 & 425 & 450 \\
\hline Liquid collected (mL) & 80 & 50 & 110 & 145 & 130 & 130 & 100 \\
\hline After filtration $(\mathrm{mL})$ & 60 & 40 & 100 & 130 & 120 & 120 & 90 \\
\hline Calorific value (MJ/kg) & 41.35 & 36.61 & 45.15 & 41.36 & 36.83 & 44.57 & 42.24 \\
\hline Viscosity $\left(\times 10^{-3} \mathrm{Ns} / \mathrm{m}^{2}\right)$ & 1.2699 & 1.6534 & 1.1891 & 1.2865 & 1.1995 & 1.2066 & 1.2245 \\
\hline Density (g/cc) & 0.8581 & 0.9745 & 0.8635 & 0.9471 & 0.9106 & 0.9265 & 0.8785 \\
\hline Flash point $\left({ }^{\circ} \mathrm{C}\right)$ & $<32$ & - & $<32$ & $<32$ & $<32$ & $<32$ & $<32$ \\
\hline Fire point $\left({ }^{\circ} \mathrm{C}\right)$ & $\leq 32$ & - & 36 & 34 & 36 & 35 & 34 \\
\hline Cloud point $\left({ }^{\circ} \mathrm{C}\right)$ & -3 & - & -2 & -3 & -3 & -2 & -2 \\
\hline Pour point $\left({ }^{\circ} \mathrm{C}\right)$ & -13 & - & -12 & -12 & -13 & -13 & -12 \\
\hline
\end{tabular}

temperature water is supplied to the condenser for the cooling action. The low boiling fractions of the vapour fraction will be condensed and collected in a collector fitted to the condenser 1 . The remaining uncondensed fraction moves to the condenser 2 . The cooling water for condenser is at a temperature of $10^{\circ} \mathrm{C}$. This low temperature for water is provided by an external refrigeration setup. The low boiling components moving through condenser 2 will be condensed and collected in a collector. The remaining uncondensed part escapes to the atmosphere.

The oil samples are produced without using catalysts and also in the presence of catalysts such as barium carbonate, zeolite 1 (pore size $\sim 4 \AA$ ), silica alumina 1 (SA1) (silica $(\sim 30 \mathrm{~nm}) 83.3 \%$, alumina $(\sim 30 \mathrm{~nm}) 16.7 \%)$, silica alumina 2 (SA2) (silica $21.1 \%$, alumina 78.9\%), SA1 + Z1 (70\% SA1, 30\% $\mathrm{Z1}$ ), and zeolite 2 (sodium Y zeolite), at reaction temperatures ranging from $400^{\circ} \mathrm{C}$ to $550^{\circ} \mathrm{C}$.

The polythene waste is first shredded to sizes of $1-2 \mathrm{~cm}$ and then mixed with the test catalyst (polymer to catalyst ratio of $10: 1$ ) uniformly in the two roll mill with friction ratio of $1: 1.4$. The mixed plastic and catalyst are then inserted into the heater assembly and are heated to the required temperature of approximately $400^{\circ} \mathrm{C}$. An inert gas (nitrogen) is passed through the heater assembly so as to prevent any kind of oxidation reaction that may take place. Once the temperature is attained, it is maintained for a preset reaction time (say 3 hours). After the reaction time is over, the heater is switched off, but the reaction is allowed to take place for another one more hour, so that maximum volatile fraction formed will pass through the two heat exchangers. The condensed volatile fraction is finally collected from the collecting tanks and is filtered. Now the process is repeated for different temperatures for various catalysts.

\section{Yield of Bio-Oil and Oil Properties}

Out of the oil samples produced by different catalysts at different temperatures, the samples which showed optimum liquid yield for a particular catalyst are shown along with their properties in Table 2 . It was noted that the liquid yield was available only at temperatures above $350^{\circ} \mathrm{C}$ for all catalysts. With the increase in temperature, the liquid yield decreased after a particular temperature (which was different for different catalyst). Finally, above $600^{\circ} \mathrm{C}$ no liquid yield was obtained for any catalyst thereby making the liquid yield gate between 400 and $550^{\circ} \mathrm{C}$. Along with the oil obtained, a gel portion was also present along with the impurities which was filtered and removed. From the obtained results of liquid yield and its properties, the catalyst combination of silica alumina 1 and zeolite 1 (70\% SA1, 30\% Z1) is selected as the best catalyst with the optimum reaction temperature as $425^{\circ} \mathrm{C}$. The oil produced using this optimum catalyst was used for GC-MS and was produced in adequate amount for the preparation of blends for testing in the engine.

\section{Chemical Composition of the Oil Sample}

Gas chromatography-mass spectrometry (GC-MS) of the selected oil sample was done to examine its chemical composition. Chloroform was used as the solvent for the oil sample. The mass spectrum shows a number of peaks showing that the oil is a mixture of a number of compounds. The compounds vary from $\mathrm{C}_{9}$ to $\mathrm{C}_{19}$, showing clear similarities to diesel in addition to the oil properties showing closeness to that of diesel. The mass spectrum is shown in Figure 3.

The list of compounds shown in the mass spectrum, along with the area $\%$ is listed in the Table 3. From the area \%, the average chemical formula of the sample oil can be calculated and is obtained as $\mathrm{C}_{13.18} \mathrm{H}_{23.56}$ (the average chemical formula of diesel is $\mathrm{C}_{12} \mathrm{H}_{23}$ ). The equation for the complete combustion of the plastic oil is as follows:

$$
\begin{aligned}
\mathrm{C}_{13.8} \mathrm{H}_{23.56}+19.07 \mathrm{O}_{2}+19.07\left(3.76 \mathrm{~N}_{2}\right) \\
\longrightarrow 13.18 \mathrm{CO}_{2}+11.78 \mathrm{H}_{2} \mathrm{O}+71.7 \mathrm{~N}_{2}
\end{aligned}
$$

The theoretical air fuel ratio of the plastic oil is found to be 14.47. Due to the close similarities of the properties of the oil with diesel, the performance test of the oil is done in a CI engine.

\section{Performance Test of the Blends in a CI Engine}

The experimental setup consists of a single cylinder Kirloskar CI engine ( $5 \mathrm{hp}, 1500 \mathrm{rpm}, 4$ stroke, and $500 \mathrm{cc}$ ), which is 
TIC: 1234.D \data.ms

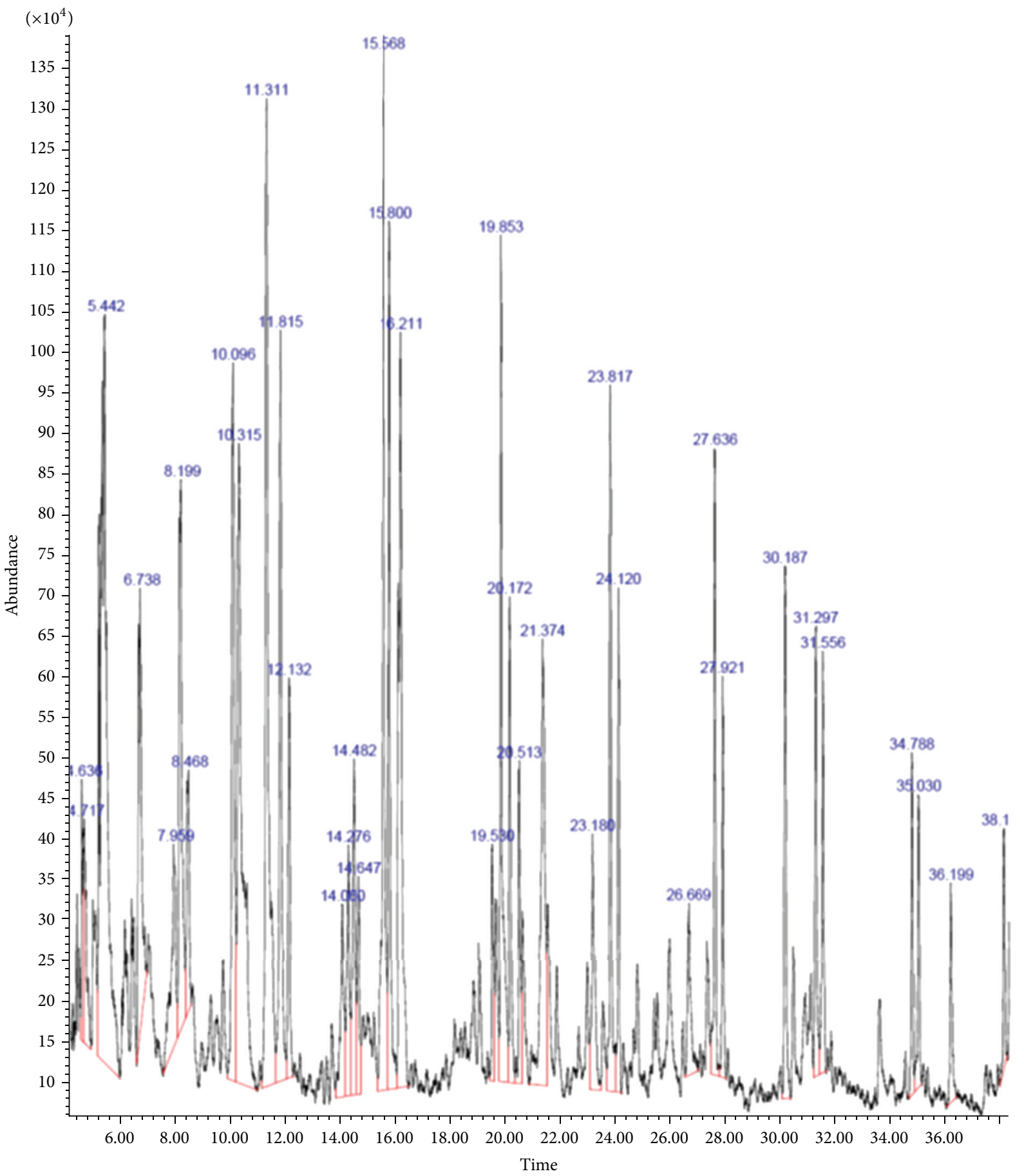

FIgURE 3: Mass spectrum of plastic oil sample (GC-MS).

mechanically loaded by means of a brake drum dynamometer. The performance of plastic oil blends in a CI engine was investigated and compared with pure diesel. Five blends of the oil were prepared. It includes B10 (10\% oil and 90\% diesel), B20 (20\% oil and 80\% diesel), B30 (30\% oil and 70\% diesel), B50 (50\% oil and 50\% diesel), and B80 (80\% oil and 20\% diesel). The engine is run using the above seven oils, and the results are compared.
The variation of fuel consumption with brake power is shown in Figure 4. With the increase in brake power the engine requires more energy and hence more fuel causing an increase in fuel consumption. It can be seen from the figure that with the increase in the concentration of the plastic oil in the blends, the fuel consumption goes on increasing; the reason is the plastic oil has a lesser calorific value than diesel (lower calorific value of plastic oil: $41.89 \mathrm{MJ} / \mathrm{kg}$ ). 
TABLE 3: Chemical composition of plastic oil sample.

\begin{tabular}{|c|c|c|c|c|}
\hline Peak & Retention time (min.) & Composition & Chemical formula & Area \% \\
\hline 4 & 6.738 & Indene & $\mathrm{C} 9 \mathrm{H} 8$ & 6.28 \\
\hline 5 & 7.96 & 2-Butenyl-benzene & $\mathrm{C} 10 \mathrm{H} 12$ & 3.94 \\
\hline 6 & 8.201 & 1-Undecene & $\mathrm{C} 11 \mathrm{H} 22$ & 7.39 \\
\hline 11 & 11.817 & 1-Dodecene & $\mathrm{C} 12 \mathrm{H} 24$ & 7.88 \\
\hline 12 & 12.314 & Dodecane & $\mathrm{C} 12 \mathrm{H} 26$ & 3.39 \\
\hline 13 & 14.062 & 1,3-Dimethyl-1H-indene & $\mathrm{C} 11 \mathrm{H} 14$ & 2.91 \\
\hline 14 & 14.278 & 1,3-Dimethyl-1H-indene & $\mathrm{C} 11 \mathrm{H} 12$ & 3.39 \\
\hline 18 & 15.8 & 1-Tridecene & $\mathrm{C} 13 \mathrm{H} 26$ & 7.41 \\
\hline 19 & 16.21 & 2-Methyl-naphthalene & C11H10 & 10.95 \\
\hline 21 & 19.851 & 1-Tetradecene & $\mathrm{C} 14 \mathrm{H} 28$ & 8.42 \\
\hline 22 & 20.172 & Tetradecane & $\mathrm{C} 14 \mathrm{H} 30$ & 3.84 \\
\hline 23 & 20.515 & 2,7-Dimethyl naphthalene & $\mathrm{C} 12 \mathrm{H} 12$ & 2.79 \\
\hline 26 & 23.818 & 1-Pentadecene & $\mathrm{C} 15 \mathrm{H} 30$ & 5.99 \\
\hline 27 & 24.122 & Pentadecane & C15H32 & 3.88 \\
\hline 29 & 27.636 & 1-Hexadecene & $\mathrm{C} 16 \mathrm{H} 32$ & 4.84 \\
\hline 30 & 27.919 & Hexadecane & C16H34 & 2.89 \\
\hline 32 & 31.298 & 3-Heptadecene & C17H34 & 3.57 \\
\hline 33 & 31.556 & Heptadecane & C17H36 & 3.55 \\
\hline 34 & 34.787 & 1-Octadecene & $\mathrm{C} 18 \mathrm{H} 36$ & 2.42 \\
\hline 35 & 35.032 & Pentadecane & $\mathrm{C} 18 \mathrm{H} 37$ & 2.4 \\
\hline 37 & 38.123 & 1-Nonadecene & С19H38 & 1.76 \\
\hline
\end{tabular}

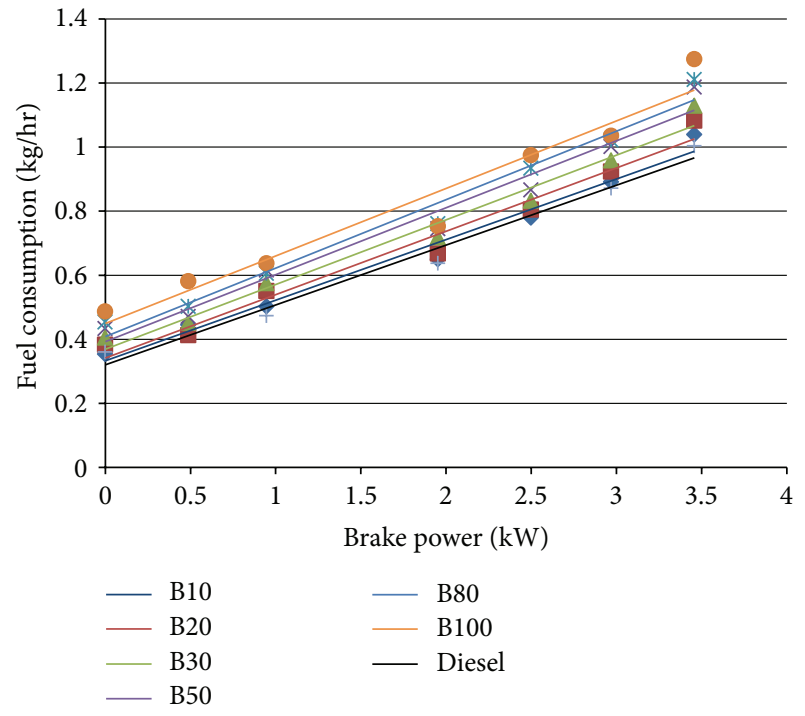

Figure 4: Fuel consumption versus brake power.

The variation of brake thermal efficiency with brake power is shown in Figure 5. Brake thermal efficiency is defined as the ratio of brake power output to the net input power. Brake thermal efficiency increases with brake power only up to a limit beyond which it drops due the incomplete combustion taking place. Here, with increase in the concentration of plastic oil in the blends, the efficiency decreases which is due to the higher fuel consumption, and the pure plastic oil gives the least efficiency.

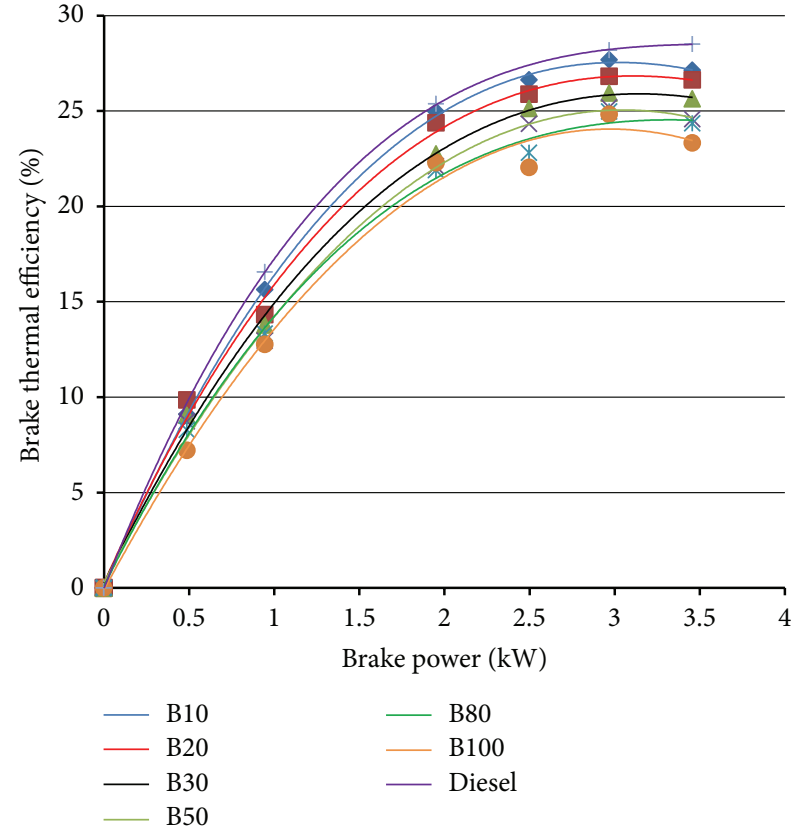

FIGURE 5: Brake thermal efficiency versus brake power.

The variation of indicated thermal efficiency with brake power is shown in Figure 6. Indicated thermal efficiency is defined as the ratio of indicated power output to the input power. Even though the frictional power increases with the blend \%, the blends show less efficiency because of its higher fuel consumption. Interestingly it can be noticed in the figure 


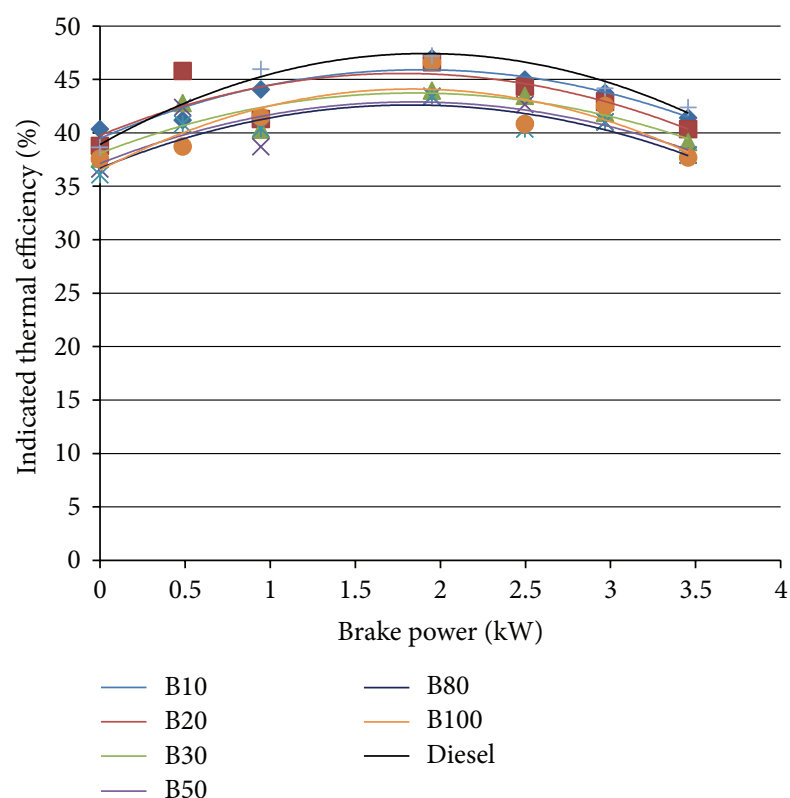

FIGURE 6: Indicated thermal efficiency versus brake power.

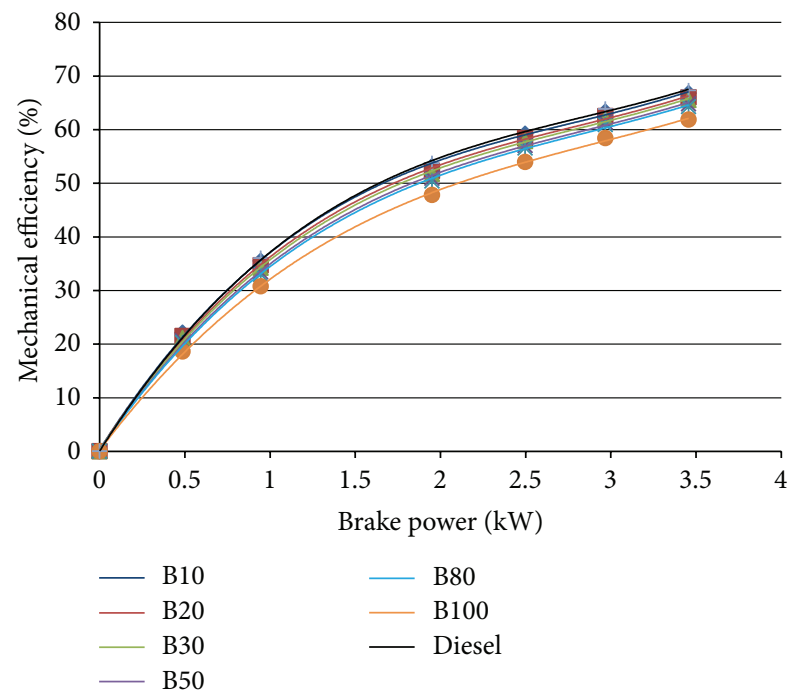

FIGURE 7: Mechanical efficiency versus brake power.

that the higher blends and pure oil show a higher efficiency than its lower counterparts. This is because the increase in frictional power is less for higher blends as compared to lesser blends.

The variation of mechanical efficiency with brake power is shown in Figure 7. Mechanical efficiency is defined as the ratio of brake power to the indicated power. It can be seen that the mechanical efficiency decreases with the increase in blend concentration. This can be attributed to the increase in frictional power with the increase in blend \%.

The variation of volumetric efficiency with brake power is shown in Figure 8. Since the test engine is a constant speed engine, volumetric efficiency remains the same irrespective of the fuel used.

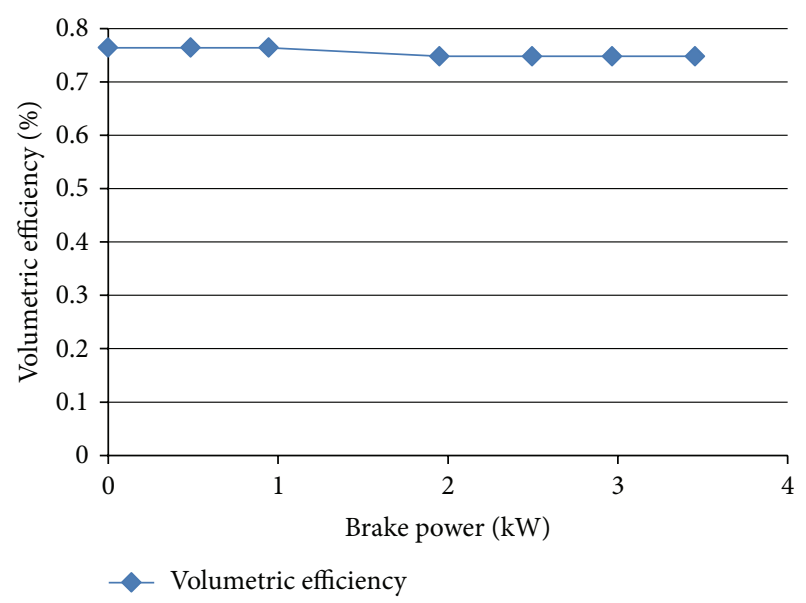

Figure 8: Volumetric efficiency versus brake power.

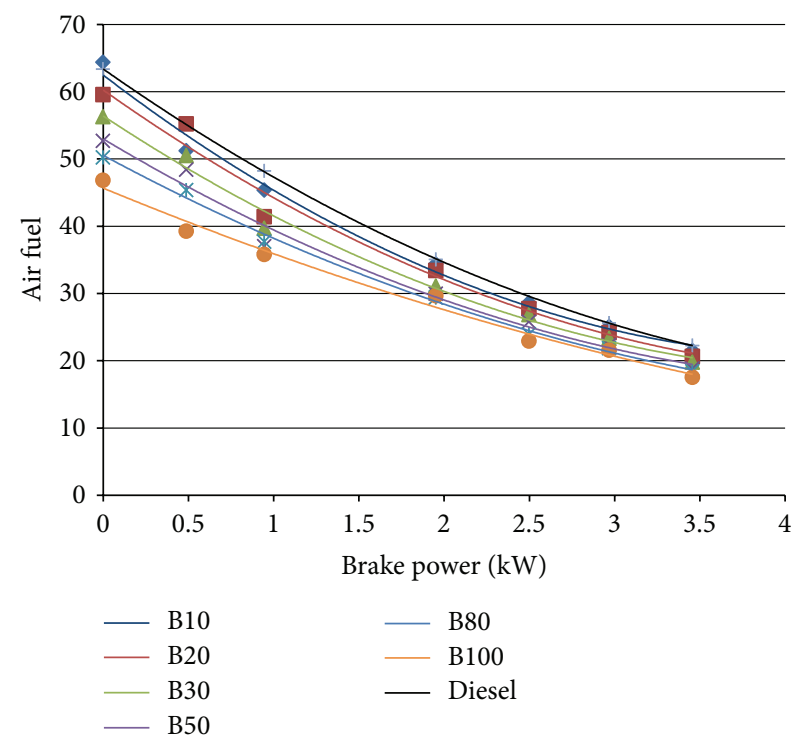

FIgURE 9: Air fuel ratio versus brake power.

The variation of air-fuel ratio with brake power is shown in Figure 9. With increase in brake power, more will be the fuel consumption, and hence the air to fuel ratio will be decreasing. From the figure it can be seen that the air fuel ratio is going on decreasing with increase in the plastic oil concentration, which is due to the increasing fuel consumption with increasing blend \%.

The variation of brake specific fuel consumption with brake power is shown in Figure 10. Brake specific fuel consumption is defined as the amount of fuel required for producing unit brake power. The plastic oil and its blends have higher bsfc than diesel because of their higher fuel consumption arising from their lesser calorific value than diesel.

\section{Emission Characteristics}

From the performance test analysis it can be seen that the test results of B20 (20\% plastic oil and 80\% diesel blend) showed 


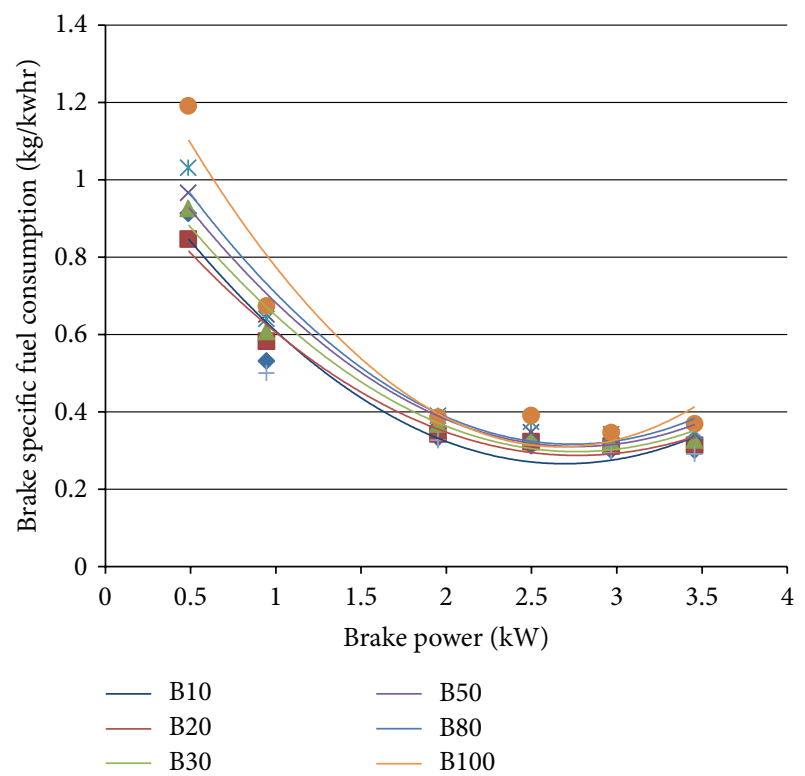

FIGURE 10: Brake specific fuel consumption versus brake power.

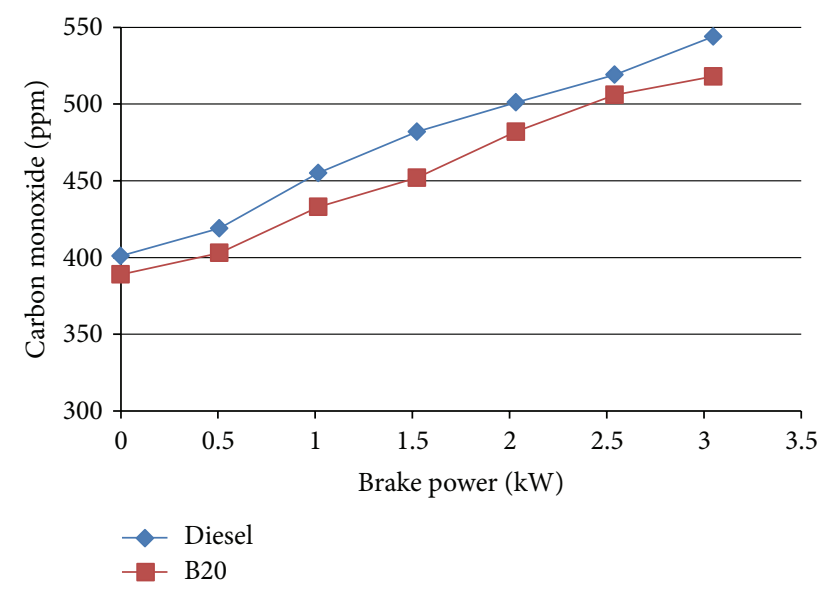

FIGURE 11: Carbon monoxide emission (ppm) versus brake power.

close similarities with that of diesel. So for the analysis of the emission characteristics, the engine was run with B20 and diesel, and the emission was analysed using an exhaust gas analyser. Emissions analysed were $\mathrm{CO}$ emission and $\mathrm{NO}_{x}$ emission.

The variation of carbon monoxide content with brake power is compared for diesel and B20 as shown in Figure 11. It can be seen that the $\mathrm{CO}$ emission is lesser for $\mathrm{B} 20$ as compared to diesel.

From the literature, it can be seen that with plastic oil there is an ignition delay of $2.5^{\circ}$ crank angle. This ignition delay causes a steep rise in the peak pressure causing a high exhaust temperature. This is evident from Figure 12 which shows a comparison of the exhaust gas temperatures of B20 and diesel.

The variation of $\mathrm{NO}_{x}$ emission with brake power is compared for diesel and B20 as shown in Figure 13. The exhaust gas temperature drives a direct relation with the $\mathrm{NO}_{x}$

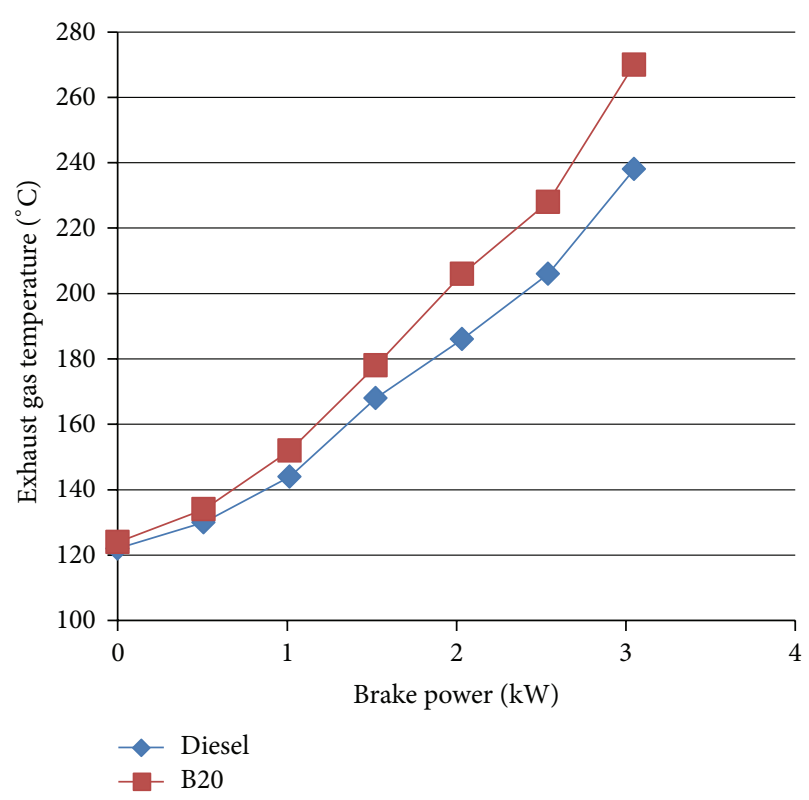

FIGURE 12: Exhaust gas temperature versus brake power.

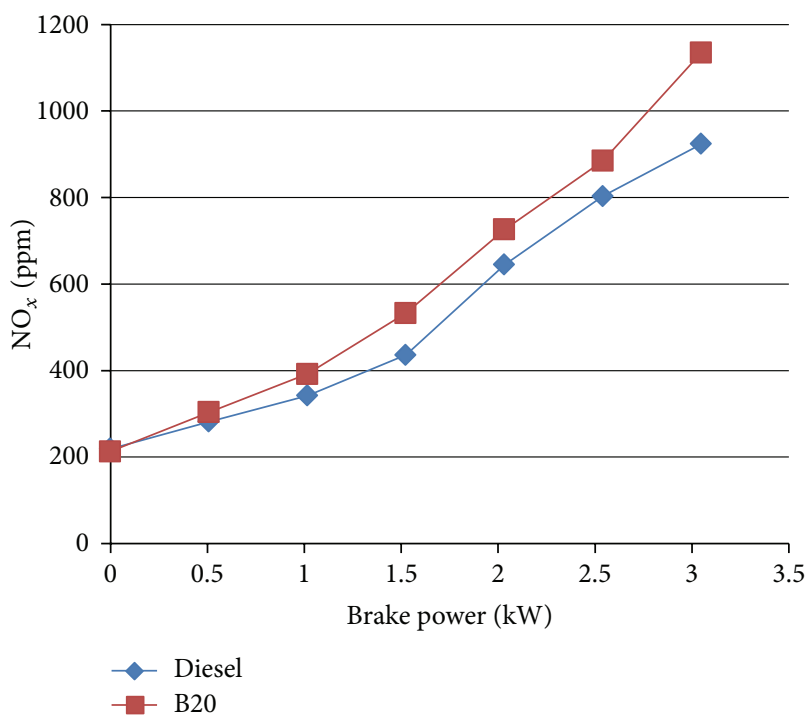

FIGURE 13: $\mathrm{NO}_{x}$ emission versus brake power.

emission. So it is clear that the B20 sample will give higher $\mathrm{NO}_{x}$ emission than with diesel.

\section{Conclusion}

(i) A petroleum based fuel has been produced from waste plastic (polythene).

(ii) The optimum catalyst and reactions for catalytic pyrolysis of polythene have been found. Based on the yield and thermophysical properties, the combination of silica alumina and zeolite 1 (pore size $\sim 4 \AA$ ) was selected as the optimum catalyst. 
(iii) The properties of the plastic oil and its chemical composition have been examined. The average chemical formula was found to be $\mathrm{C}_{13.18} \mathrm{H}_{23.56}$, and hence the performance analysis was done in a CI engine.

(iv) In the performance analysis in engine, even though the plastic oil shows inferior results as compared to diesel, the lower blends percentage oils show results close with that of diesel (B10, B20, and B30). This makes it a strong competitor in the area of alternate fuels. Also the blend B20 has low CO emissions than for diesel. However, the $\mathrm{NO}_{x}$ emissions are higher for B20.

(v) $64.15 \%$ of the production cost is accounted for the cost of catalysts. If cheaper catalysts can be employed, the production cost can be decreased considerably.

(vi) If the gaseous products and solid can be used, then the effective cost will come down even further.

(vii) Rather than considering it just as an alternate fuel, the practical importance of this method in waste plastic management adds its value as an alternate fuel.

\section{References}

[1] A. K. Panda, R. K. Singh, and D. K. Mishra, "Thermolysis of waste plastics to liquid fuel: a suitable method for plastic waste management and manufacture of value added products: a world prospective," Renewable and Sustainable Energy Reviews, vol. 14, no. 1, pp. 233-248, 2010.

[2] http://cipet.gov.in/plastics_statics.html.

[3] A. R. Songip, T. Masuda, H. Kuwahara, and K. Hashimoto, "Test to screen catalysts for reforming heavy oil from waste plastics," Applied Catalysis B, vol. 2, no. 2-3, pp. 153-164, 1993.

[4] G. Manos, A. Garforth, and J. Dwyer, "Catalytic degradation of high-density polyethylene on an ultrastable-Y zeolite. Nature of initial polymer reactions, pattern of formation of gas and liquid products, and temperature effects," Industrial and Engineering Chemistry Research, vol. 39, no. 5, pp. 1203-1208, 2000.

[5] M. A. Uddin, K. Koizumi, K. Murata, and Y. Sakata, "Thermal and catalytic degradation of structurally different types of polyethylene into fuel oil," Polymer Degradation and Stability, vol. 56, no. 1, pp. 37-44, 1997.

[6] M. R. Jan, J. Shah, and H. Gulab, "Catalytic degradation of Waste high-density polyethylene into fuel products using $\mathrm{BaCO}_{3}$ as a catalyst," Fuel Processing Technology, vol. 91, no. 11, pp. 14281437, 2010.

[7] N. S. Akpanudoh, K. Gobin, and G. Manos, "Catalytic degradation of plastic waste to liquid fuel over commercial cracking catalysts: effect of polymer to catalyst ratio/acidity content," Journal of Molecular Catalysis A, vol. 235, no. 1-2, pp. 67-73, 2005.

[8] H. Gulab, M. R. Jan, J. Shah, and G. Manos, "Plastic catalytic pyrolysis to fuels as tertiary polymer recycling method: effect of process conditions," Journal of Environmental Science and Health, vol. 45, no. 7, pp. 908-915, 2010. 


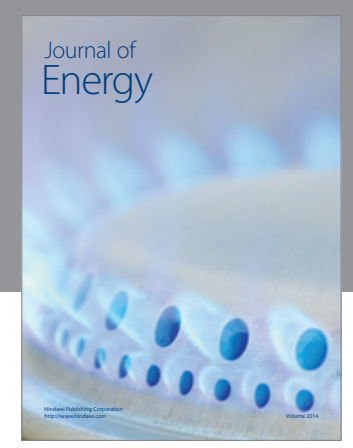

Journal of

Industrial Engineering
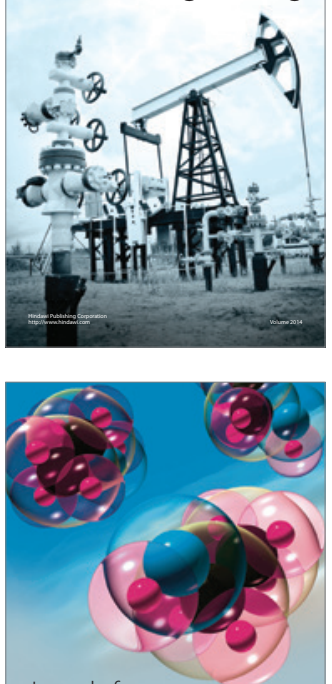

Fuels
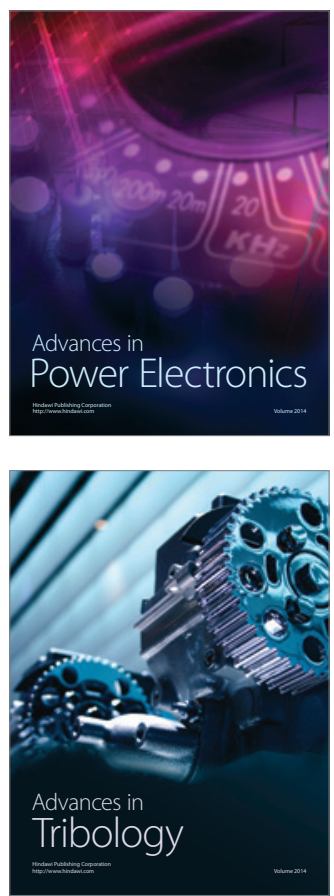

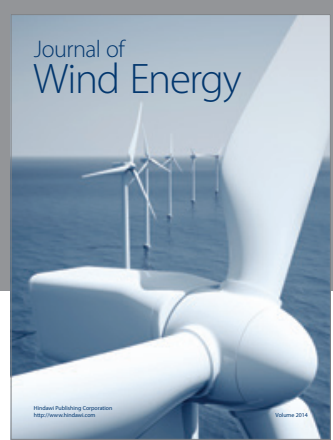

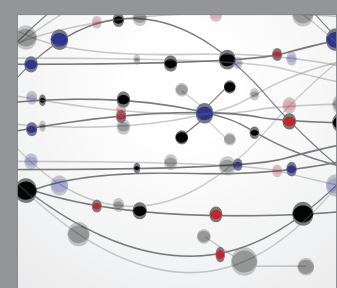

The Scientific World Journal

Submit your manuscripts at http://www.hindawi.com

Journal of

Structures
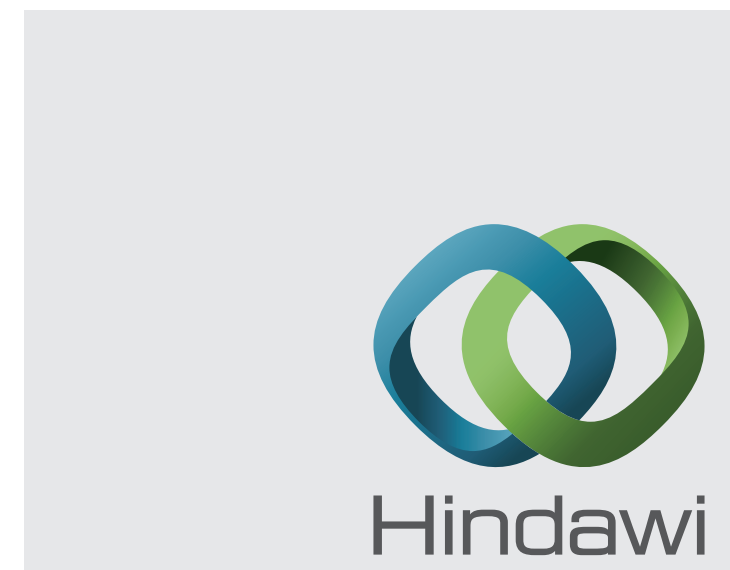

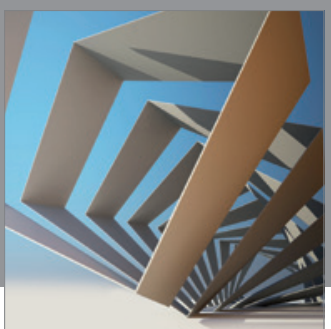

Rotating

Machinery
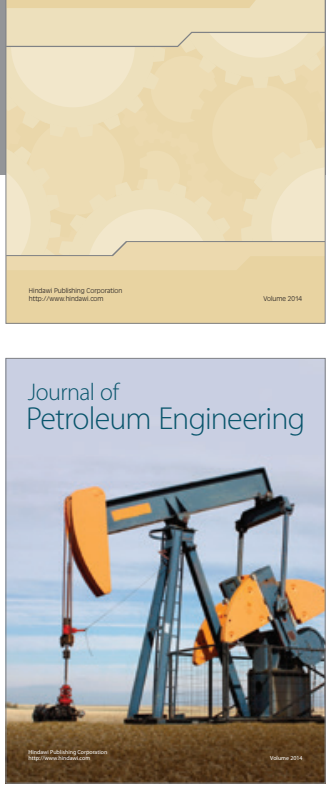

Journal of

Solar Energy
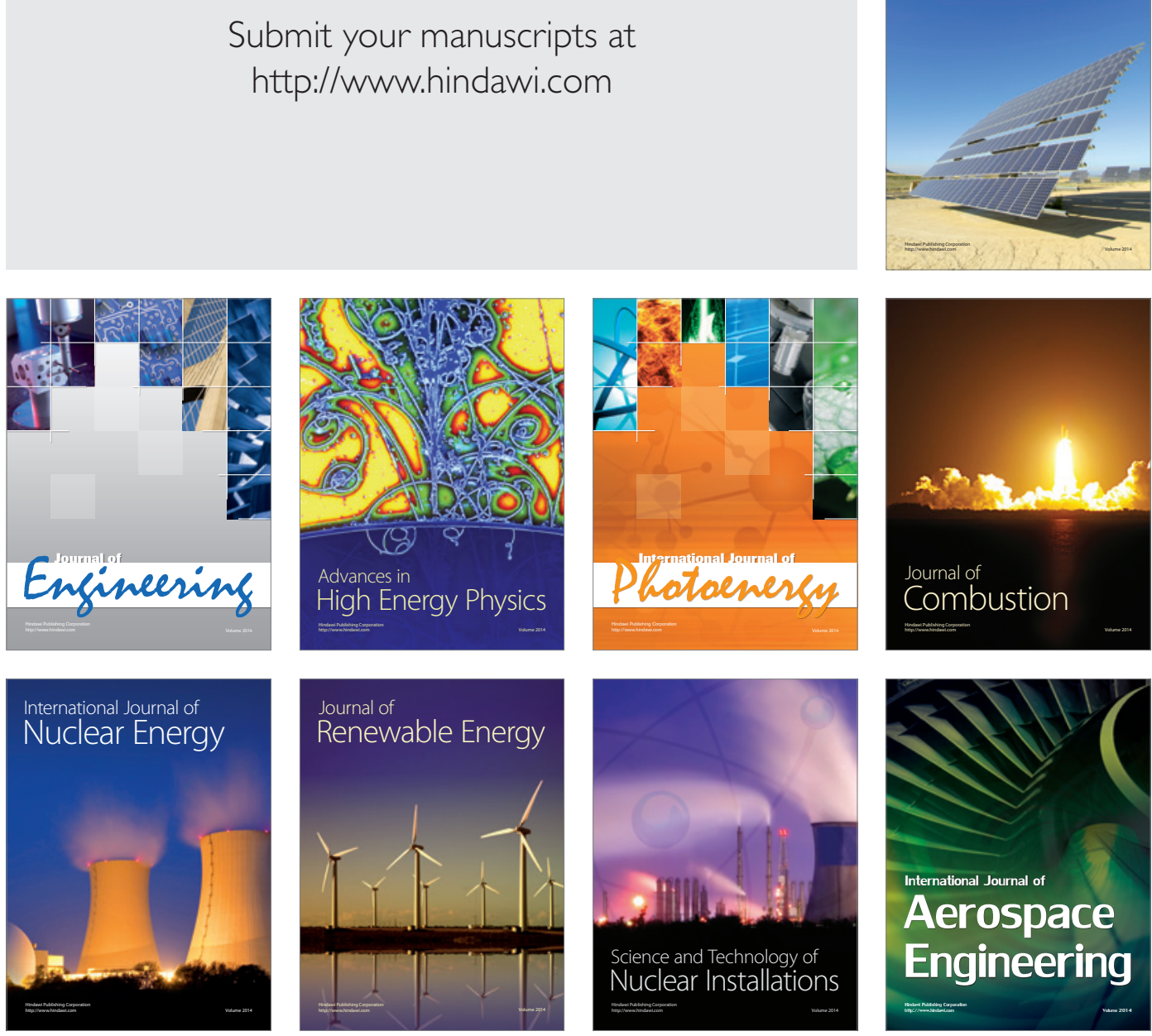